\title{
MST-312 Alters Telomere Dynamics, Gene Expression Profiles and Growth in Human Breast Cancer Cells
}

\author{
Resham Lal Gurung ${ }^{a}$ Shi Ni Lima ${ }^{a}$ Grace Kah Mun Low ${ }^{a}$ \\ M. Prakash Hande ${ }^{a, b}$ \\ ${ }^{a}$ Department of Physiology, Yong Loo Lin School of Medicine, and ${ }^{b}$ Tembusu College, \\ National University of Singapore, Singapore
}

\section{Key Words}

DNA damage/repair · Telomeres · Telomerase · Cancer chemotherapy

\begin{abstract}
Background: Targeting telomerase is a potential cancer management strategy given that it allows unlimited cellular replication in the majority of cancers. Dysfunctional telomeres are recognized as double-strand breaks. However, the status of DNA repair response pathways following telomerase inhibition is not well understood in human breast cancer cells. Here, we evaluated the effects of MST-312, a chemically modified derivative from tea catechin, epigallocatechin gallate, on telomere dynamics and DNA damage gene expression in breast cancer cells. Methodology: Breast cancer cells MCF-7 and MDA-MB-231 were treated with MST-312, and telomere-telomerase homeostasis, induced DNA damage and gene expression profiling were analyzed. Results: MST-312 decreased telomerase activity and induced telomere dysfunction and growth arrest in breast cancer cells with more profound effects in MDA-MB-231 than in MCF-7 cells. Consistent with these data, the telomere-protective protein TRF2 was downregulated in MDA-MB-231 cells. MST-312 induced DNA damage at telomeres accompanied by reduced expression of DNA damage-related genes ATM and RAD50. Co-treatment with MST312 and the poly(ADP-ribose) polymerase 1 (PARP-1) inhibitor PJ-34 further enhanced growth reduction as compared to single treatment with MST-312 or PJ-34. Conclusions: Our work demonstrates potential importance for the establishment of antitelomerase cancer therapy using MST-312 along with PARP-1 inhibition in breast cancer therapy.

(c) 2015 S. Karger AG, Basel
\end{abstract}

This paper was presented at the 8th Congress of the International Society of Nutrigenetics/Nutrigenomics (ISNN), Gold Coast, Qld., Australia, May 2-3, 2014. 
Gurung et al:: MST-312 Alters Telomere Dynamics, Gene Expression Profiles and Growth in Human Breast Cancer Cells

\section{Introduction}

A hallmark of cancer is its unlimited proliferation potential, and in the majority of cancer cells this is predominantly due to reactivation of telomerase enzyme [1,2]. Telomerase enzyme consists of core components, reverse transcriptase (TERT) and RNA template (TERC), and other associated proteins [3]. Telomerase is expressed in most tissues only during the first few weeks of embryogenesis, whereas in normal adult somatic cells, telomerase activity is minimal or undetectable [4]. However, reactivation of telomerase in cancer cells counteracts the shortening of telomeres during each cell division. In cancer cells which do not express telomerase, telomeres are maintained by the alternate lengthening of telomeres pathway which is thought to be mediated by homologous recombination (HR) [5].

Telomeres shorten by $50-150$ bp every cell division due to the end-replication problem, a phenomenon whereby DNA polymerase is unable to replicate the ends of chromosomes completely, and progressive shortening of telomeres to critical length induces senescence or apoptosis in primary human somatic cells where telomerase is absent [6, 7]. Telomeres, present at the ends of eukaryotic chromosomes, function to protect the chromosome ends from nucleolytic degradation, fusion and unwanted DNA damage recognition [8, 9]. Telomeres are masked by shelterin proteins which act as a protective cap and distinguish telomeric ends from the site of double-strand breaks (DSBs). Shelterin proteins consist of telomeric restriction fragment 1 (TRF1), TRF2, TIN2, TPP1, POT1 and RAP1. TRF1, TRF2 and POT1 bind directly to telomere repeats and are interconnected by TIN2, TPP1 and Rap1 [see 11]. Shelterin complex is critical for this function, and accumulation of these proteins at telomeres is dependent on telomere length [10]. Expression of TRF1 is inversely proportional to telomere length, while TRF2 is essential in the formation of the protective cap [9, 11]. Inhibition of TRF2 induces p53- and ataxia telangiectasia mutated (ATM)-dependent apoptosis [12].

Due to the discrepancy in telomerase expression between normal somatic cells and cancer cells, telomerase activity could provide a potential target for specific anticancer therapies. Telomeres are of shorter length in cancer cells as compared to those in normal somatic cells as well as germline cells. Furthermore, it is suggested that the rapid proliferation rate of cancer cells could make them more susceptible to crisis following telomerase inhibition compared to germline cells with normal telomerase activity [13]. Several studies have shown that MST-312 inhibits telomerase activity and induces growth arrest selectively in tumor cells [14-16]. MST-312, an analogue of the green tea epigallocatechin gallate (EGCG), provides a chemically more stable alternative EGCG while retaining the ability to inhibit telomerase activity. Moreover, MST-312 ( $\left.\mathrm{IC}_{50}=0.67 \mu \mathrm{M}\right)$ is more potent than EGCG $\left(\mathrm{IC}_{50}=\sim 1 \mu \mathrm{M}\right)$ [15]. The chromane ring and the ester linkage in EGCG were modified to a chromone ring and an amide linkage, respectively. While the hydroxy groups on the original chromane ring were deleted, the 3,4-dihydroxy groups on each phenyl ring are important for the potent inhibition of telomerase activity.

Numerous DNA repair proteins have also been reported to play a role in telomere maintenance. Poly(ADP-ribose) polymerases (PARPs) are involved in the repair of single-strand breaks and add ribose moiety using NAD+ as a substrate in posttranslational modification of histones and other nuclear proteins that contributes to the survival of cells following DNA damage [17]. Members of the PARP family such as PARP-1 and tankyrase have been shown to affect telomere length directly or via posttranslational modification of shelterin proteins TRF1 and TRF2 which increase accessibility of telomerase to telomeres [18-20]. Targeting both telomerase activity and accessibility could be an alternative strategy to enhance antitumor effects and circumvent the possibility of drug resistance. 
Although it is well established that dysfunctional telomeres are recognized as DSBs, the status of the DNA damage response pathway(s) following telomerase inhibition in cancer cells is not well studied. Here, we examined the effect of MST-312 on telomerase activity in breast cancer cells, MCF-7 and highly metastatic MDA-MB-231 cells, after which the immediate and long-term effects of telomerase inhibition were investigated. We elucidated, in particular, the effect of telomerase inhibition on the DNA damage response pathway in breast cancer cells following exposure to MST-312.

\section{Materials and Methods}

\section{Cells and Drug Treatment}

Human breast carcinoma cells, MCF-7 (HTB-22) and MDA-MB-231 (HTB-26), were grown in RPMI-1640 supplemented with $10 \%$ heat-inactivated fetal bovine serum (Hyclone, USA) and $100 \mathrm{U} / \mathrm{ml}$ of penicillin/ streptomycin (Gibco, USA). MCF-10A (CRL-10317) spontaneously immortalized noncancerous epithelial cells were grown in complete MEGM medium (Lonza, Switzerland) supplemented with 10\% FBS (Hyclone) and $100 \mathrm{U} / \mathrm{ml}$ penicillin/streptomycin. Cell types were obtained from American Type Culture Collection, USA. All cells were maintained in a humidified $5 \% \mathrm{CO}_{2}$ incubator at $37^{\circ} \mathrm{C}$. Stock solution of MST-312 (Merck, USA) was prepared in dimethyl sulfoxide (DMSO), and suitable working concentrations were made from the stock in complete medium.

\section{Assay for Cell Viability}

Following $48 \mathrm{~h}$ of MST-312 treatment, attached cells were washed once with phosphate-buffered saline (PBS). Crystal violet solution $(0.75 \%$ crystal violet in $50 \%$ ethanol:distilled water with $1.75 \%$ formaldehyde and $0.25 \% \mathrm{NaCl}$ ), which stains DNA by binding electrostatically to nuclear proteins, was added to the wells and incubated for $20 \mathrm{~min}$ at room temperature. To remove excess crystal violet solution, cells were washed with PBS solution and wells were air dried. 1\% sodium dodecyl sulphate:PBS was added to lyse the cells and solubilize the dye. The amount of crystal violet taken up by cells at 595-nm absorbance was measured using an automated ELISA reader. In addition, the CellTiter-Glo ${ }^{\circledR}$ Luminescent Cell Viability Assay (Promega, USA) was used to determine the number of viable cells following treatment with $10 \mu \mathrm{M} \mathrm{PJ-34,} \mathrm{a} \mathrm{potent} \mathrm{PARP-1}$ inhibitor [21], or/and MST-312 for $72 \mathrm{~h}$ in culture.

\section{Cell Cycle Analysis}

Following $48 \mathrm{~h}$ of MST-312 treatment, cells were harvested, washed in $0.1 \%$ bovine serum albumin (BSA) PBS, fixed in 70\% ethanol:1× PBS and stained with propidium iodide (Sigma, USA) RNase A (Roche, USA; $2 \mathrm{mg}$ propidium iodide and $2 \mathrm{mg}$ RNaseA $/ 100 \mathrm{ml} 0.1 \%$ BSA in $1 \times$ PBS). Samples were analyzed by flow cytometry (FACSCalibur ${ }^{\mathrm{TM}}$, Becton Dickinson, USA) at 488-nm excitation $\lambda$ and $610-\mathrm{nm}$ emission $\lambda$. A total of 10,000 events were analyzed. Data obtained were analyzed using WINMDI software.

\section{Western Blot Analysis}

Total cellular proteins were isolated from control and MST-312-treated cells using RIPA (radioimmunoprecipitation assay) buffer (1\% nonidet P- $40,1 \%$ sodium deoxycholate, $0.1 \%$ SDS, $0.15 \mathrm{M} \mathrm{NaCl}, 0.01 \mathrm{~m}$ sodium phosphate, $2 \mathrm{~mm}$ EDTA, $50 \mathrm{~mm}$ sodium fluoride, $0.2 \mathrm{~mm}$ sodium vanadate and $100 \mathrm{U} / \mathrm{ml}$ aprotinin, $\mathrm{pH}$ 7.2). The whole cell lysate was recovered by centrifugation at $14,000 \mathrm{rpm}$ for $10 \mathrm{~min}$, and protein concentration was determined by the bicinchoninic acid method using an assay kit (Pierce Biotechnology, USA) with BSA as a standard. Western blot analyses of ATM, p53, p21, cyclin B, TRF2, survivin, hTERT and $\beta$-actin (Santa Cruz Biotechnology, USA) and p-ATM (Ser1981; Genetex, USA) were performed using specific antibodies.

Alkaline Single-Cell Gel Electrophoresis Assay

After treatment with MST-312, breast cancer cells were harvested and resuspended in Hank's balanced salt solution (Sigma) with 10\% DMSO and 0.5 M EDTA. The cell suspension was then suspended in $0.7 \%$ lowmelting agarose at $37^{\circ} \mathrm{C}$ (Conda, Spain), and layered onto comet slides (Trevigen, USA). The cells were then lysed in lysis solution containing $2.5 \mathrm{M} \mathrm{NaCl}, 100 \mathrm{~mm} \mathrm{pH} 8.0 \mathrm{EDTA}, 10 \mathrm{~mm}$ Tris-HCL and $1 \%$ Triton-X at $4{ }^{\circ} \mathrm{C}$ for $1 \mathrm{~h}$. Denaturation was carried out for $40 \mathrm{~min}$ in chilled alkaline electrophoresis buffer ( $\mathrm{pH}$ 13.0-13.7). Electrophoresis was subsequently carried out for $20 \mathrm{~min}$. Slides were immersed in neutralization buffer ( 500 


\section{Nutrigenomics}

mM Tris-HCL, pH 7.4), dehydrated, dried and stained with SYBR Green dye (Trevigen) and scored with Comet Analysis Software (Metasystems, Germany). The images were captured using Zeiss Axioplan 2 imaging fluorescence microscope (Carl Zeiss, Germany) equipped with a triple-band filter. One hundred comets per sample were randomly selected and analyzed. The extent of DNA damage was expressed as the tail moment, which corresponded to the fraction of the DNA in the tail of the comet.

\section{Telomere Repeat Amplification Protocol}

Telomerase activity detection was performed with the commercially available TRAPeze ${ }^{\circledR}$ XL Telomerase Detection Kit (Chemicon International, USA). All steps were done according to the manufacturer's instructions.

\section{Telomere Restriction Fragment Length Analysis}

DNA extraction was performed according to the manufacturers' protocol using DNeasy Tissue Kit (Qiagen, USA). The telomere restriction fragment (TRF) length analysis assay was performed using the TeloTAGGG Length Assay Kit (Roche Applied Science, USA). The Kodak Gel imaging system and Kodak imaging software were used to calculate the quantitative measurements of the mean TRF length.

\section{Quantitative Fluorescence in situ Hybridization Analysis}

Cells were arrested at mitosis by treatment with colcemid $(0.1 \mathrm{mg} / \mathrm{ml})$ and subsequently incubated with a hypotonic solution of potassium chloride at $37^{\circ} \mathrm{C}$ for $15 \mathrm{~min}$ followed by fixation in Carnoy's fixative. Quantitative fluorescence in situ hybridization (Q-FISH) was performed using the telomere-specific peptide nucleic acid probe labelled with Cy3 as described [22]. Metaphase spreads for different samples were hybridized simultaneously. To avoid selection bias, good and well-spread metaphases were randomly chosen for analysis. Images were acquired on the same day (within $4 \mathrm{~h}$ ) for all the samples using the Zeiss Axioplan 2 imaging fluorescence microscope. Fluorescence intensity of telomere signals was measured in 10-15 metaphases using the in situ imaging software (Metasystems, Germany).

\section{Immunofluorescence}

Briefly, $5 \times 10^{4}$ breast cancer cells were plated on coverslips in 6-well plates and grown for $48 \mathrm{~h}$ in the presence of $1.0 \mu \mathrm{M}$ MST-312. Cells were fixed in $4 \%$ paraformaldehyde and permeabilized in $0.1 \%$ Triton-X100. Following incubation with anti-phospho-H2AX (Ser139; Upstate Biotechnology, USA) diluted in PBS with 4\% FCS and $0.1 \%$ Triton X-10, cells were washed and incubated with FITC-conjugated anti-mouse (1:500) secondary antibodies at room temperature in the dark for $1 \mathrm{~h}$. Subsequent washes were also conducted in the dark. The cover slips were sufficiently dried prior to mounting them onto slides containing Vectashield mounting media with DAPI (Vector Laboratories, USA). Fluorescent images were captured through confocal microscopy (Olympus Fluoview FV1000). Detection of telomere dysfunction-induced foci (TIF) was performed as described previously [23]. Following incubation with anti-phospho-H2AX, slides were placed in $4 \%$ formaldehyde for $20 \mathrm{~min}$ for cross-fixing to preserve antibodies following secondary antibody. Subsequently, hybridization with telomeric peptide nucleic acid probe was performed as described above with the exception that TBS-T was used for washing instead of PBS.

\section{Gene Expression Analysis}

The total RNA was extracted from cells treated with $1.0 \mu \mathrm{M}$ MST-312 for $48 \mathrm{~h}$ using a QIAmp RNA Blood Mini Kit (Qiagen, Hilden, Germany). The extracted RNA was quantified using NanoDrop 1000 (Thermo Scientific, USA). RNA integrity was checked using Bio-Analyzer (Agilent Technologies Inc., USA). 500 ng of extracted RNA from each sample was used for gene expression study. The total Prep RNA Amplification Kit (Ambion Inc., Tex., USA) was used for cRNA amplification process. The biotinylated amplified RNA thus generated was used for hybridization with HumanRef8 V3.0, Human Whole-Genome Expression BeadChips (Illumina Inc., USA) for $16 \mathrm{~h}$ at $58^{\circ} \mathrm{C}$. After the incubation period, the arrays were washed and stained with StreptavidinCy3 (GE Healthcare, Bio-Sciences, UK). Illumina Bead Array Reader was used to scan the arrays, and the array data thus obtained after scanning were imported and analyzed using Gene Spring 7.2 (Silicon Genetics, USA).

\section{Real-Time Polymerase Chain Reaction}

Extracted RNA was reverse transcribed with Transcriptor First Strand cDNA Synthesis Kit (Roche) using hexamer primers according to the manufacturer's instructions. Real-time polymerase chain reaction (PCR) was then performed using LightCycler ${ }^{\circledR} 480$ SYBR Green I Master (Roche) to quantify specific mRNA 
Gurung et al.: MST-312 Alters Telomere Dynamics, Gene Expression Profiles and Growth in Human Breast Cancer Cells

Table 1. Forward and reverse primer sequences of genes used in the real-time PCR

\begin{tabular}{lll}
\hline Gene name & Forward $5^{\prime} \rightarrow 3^{\prime}$ & Reverse $5^{\prime} \rightarrow 3^{\prime}$ \\
\hline SURVIVIN & GGGAAACGGGGTGAACTTCAGG & CCCGTGTGGAGAACGTGACAGA \\
H2AFX & TGGAAGACTTGGCCTTCCGC & AATCGGCGATCGCGTCTCTC \\
Cyclin $B 1$ & TCTGCTGGGTGTAGGTCCTTGG & GTTCTTGGCCTCAGTCCGGG \\
TERF2 & TGTCCAAGGACCCCACAACTCA & GATTCCGTAGCTGCCTTGCG \\
RAD50 & CATTCTGGGCGTGCGGAG & TCTTGAGCAACCTTGGGATCGTG \\
ATM & CGCGGAGACCGCGTGATA & CACTGTCACTGCACTCGGAAGG \\
GAPDH & CGTCAAGGCTGAGAACGGGAAG & GTGCAGGAGGCATTGCTGATGA \\
ACTIN & CTGGCCGGGACCTGACTGACTA & CCCAGGAAGGAAGGCTGGAAGA \\
HSP90 & ACGGCTGGACAGCCAATATGGA & TCATGCGATAGATGCGGTTGGA \\
\hline
\end{tabular}

expression of selected genes from superarray results normalized to $\beta$-actin expression under the following conditions: 5 -min initial hold at $95^{\circ} \mathrm{C}, 45$ cycles of $95^{\circ} \mathrm{C}$ for $10 \mathrm{~s}, 57^{\circ} \mathrm{C}$ for $10 \mathrm{~s}$ and $72^{\circ} \mathrm{C}$ for $15 \mathrm{~s}$, with a 1-min hold at $65^{\circ} \mathrm{C}$ before cooling to $4{ }^{\circ} \mathrm{C}$. The genes of interest with the respective primer sequences are shown in table 1. All reactions were performed simultaneously in duplicate, using $\beta$-actin as the housekeeping gene. Data were analyzed using LightCycler ${ }^{\circledR} 480$ software version 1.2.9.11.

Statistical Analysis

Statistical significance in the data sets was assessed by Student's t test using Microsoft Excel 2010 (Microsoft Corp., USA) and two-way ANOVA using GraphPad Prism. The difference was considered to be statistically significant when $\mathrm{p}<0.05$.

\section{Results}

Inhibition of Telomerase Activity and Shortening of Telomeres by MST-312 in Breast Cancer Cell Models

Basal telomerase activity was measured in both the MCF-7 and MDA-MB-231 breast cancer cells. As shown in figure 1a, MCF-7 cells showed higher telomerase activity compared to MBA-MB-231 cells. We first evaluated the effect of MST-312 on telomerase activity in breast cancer cells MCF-7 and MDA-MB-231 following 48-hour treatment with 0, 1.0 and 10 $\mu \mathrm{M}$ MST-312. As shown in figure $1 \mathrm{~b}$, telomerase activity was significantly reduced in breast cancer cells following 48-hour treatment with MST-312. The observed effect was dose dependent and more pronounced in MDA-MB-231 as compared to MCF-7 cells. A previous report has shown that, at continuous exposure to $1.0 \mu \mathrm{M}$, MST-312 induces gradual telomere shortening and reduction in cell proliferation in HTC75 cells (telomerase positive) and not in GM847 cells (alternate lengthening of telomeres) [20]. In our study, there was $\sim 40 \%$ reduction in enzyme activity in both breast cancer cell types at a dose of $1.0 \mu \mathrm{M}$ MST-312. In these cells, minimal changes in hTERC and hTERT gene expression (data not shown) and hTERT protein expression were observed (fig. 1c). These results possibly suggest that MST312-mediated reduction of telomerase activity is not linked to the regulation at the protein or gene expression level in breast cancer cells.

We next analyzed telomere length following long-term exposure of MCF-7, MDA-MB-231 and normal immortalized epithelial cells, MCF-10A, to 1.0 $\mu \mathrm{M}$ MST-312 and the effect of telomerase inhibition on average telomere length. This was evaluated by TRF assay. Exposure to MST-312 resulted in progressive telomere shortening in breast cancer cells as evidenced by a lower average molecular weight of the TRFs (fig. 2a). Surprisingly, these effects were present at early time points (day 5) in MST-312-treated MDA-MB-231 cells as compared to MST312-treated MCF-7 cells (day 15 and day 30). As the relative decrease in telomere length was 


\section{Journal of \\ Nutrigenetics \\ Nutrigenomics}

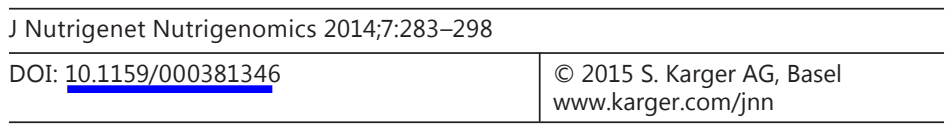

Gurung et al.: MST-312 Alters Telomere Dynamics, Gene Expression Profiles and Growth in Human Breast Cancer Cells

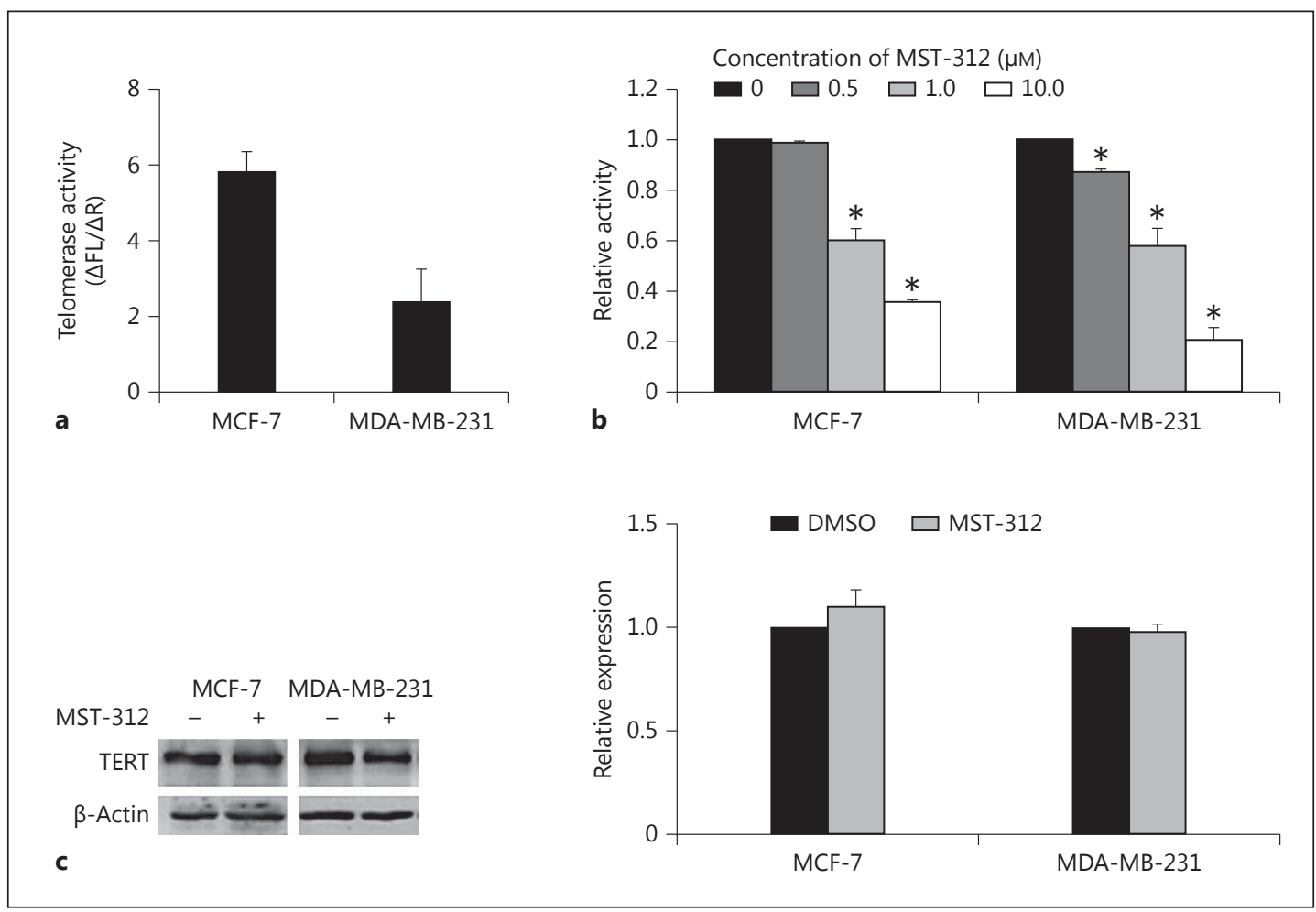

Fig. 1. MST-312 efficiently reduces telomerase activity in breast cancer cells. a Relative basal telomerase activity in MCF-7 and MDA-MB-231 breast cancer cells. Telomerase activity was determined by telomere repeat amplification protocol (TRAP) assay. $\Delta \mathrm{FL} / \Delta \mathrm{R}=$ Ratio of net fluorescein emission (telomerase activity) to net sulforhodamine emission (internal controls). $\mathbf{b}$ Telomerase activity in the breast cancer cells MCF-7 and MDA-MB-231 subjected to MST-312 (0-10 $\mu \mathrm{M})$ for $48 \mathrm{~h}$. Asterisk indicates that the change in telomerase activity as determined by the TRAP assay with respect to control is statistically significant, i.e. $p$ value $<0.05$. Data represent means \pm SE of three independent experiments. c Western blot analysis showed minimal changes in the levels of hTERT in breast cancer cells following MST-312 treatment (1.0 $\mu \mathrm{M})$ for $48 \mathrm{~h}$. Representative images from two independent experiments are displayed. Relative protein expression of hTERT in cells following 48-hour treatment with MST-312 is shown.

smaller following MST-312 treatment in MCF-7 as compared to MDA-MB-231 cells, we investigated the telomere length of individual chromosomes using Q-FISH in MCF-7 cells. Consistent with our TRF data, the exposure of MCF-7 cells to MST-312 led to a significant reduction in mean telomere length and an increase in the population of cells with shorter telomeres (fig. 2b). Next, we determined the expression of TRF2 protein in these cells. A decrease in the expression of TRF2 protein was observed following short-term treatment with MST-312 in MDA-MB-231 cells but not in MCF-10A or MCF-7 cells (fig. 2c). This is consistent with our findings that telomere shortening was observed at an earlier time point in MDA-MB-231 cells. We observed a reduction in TRF2 expression in MCF-7 cells albeit after 4 weeks of treatment with MST-312 (fig. 2d).

\section{Telomerase Inhibition by MST-312 Induces Immediate DNA Damage}

If telomerase activation facilitates DNA damage repair, telomerase inhibition should induce DNA damage as dysfunctional telomeres are often recognized as DNA damage [24]. Therefore, we examined the impact of MST-312 on DNA integrity by using comet assay under alkaline conditions, which allows the analysis of types of DNA damage such as DSBs and 


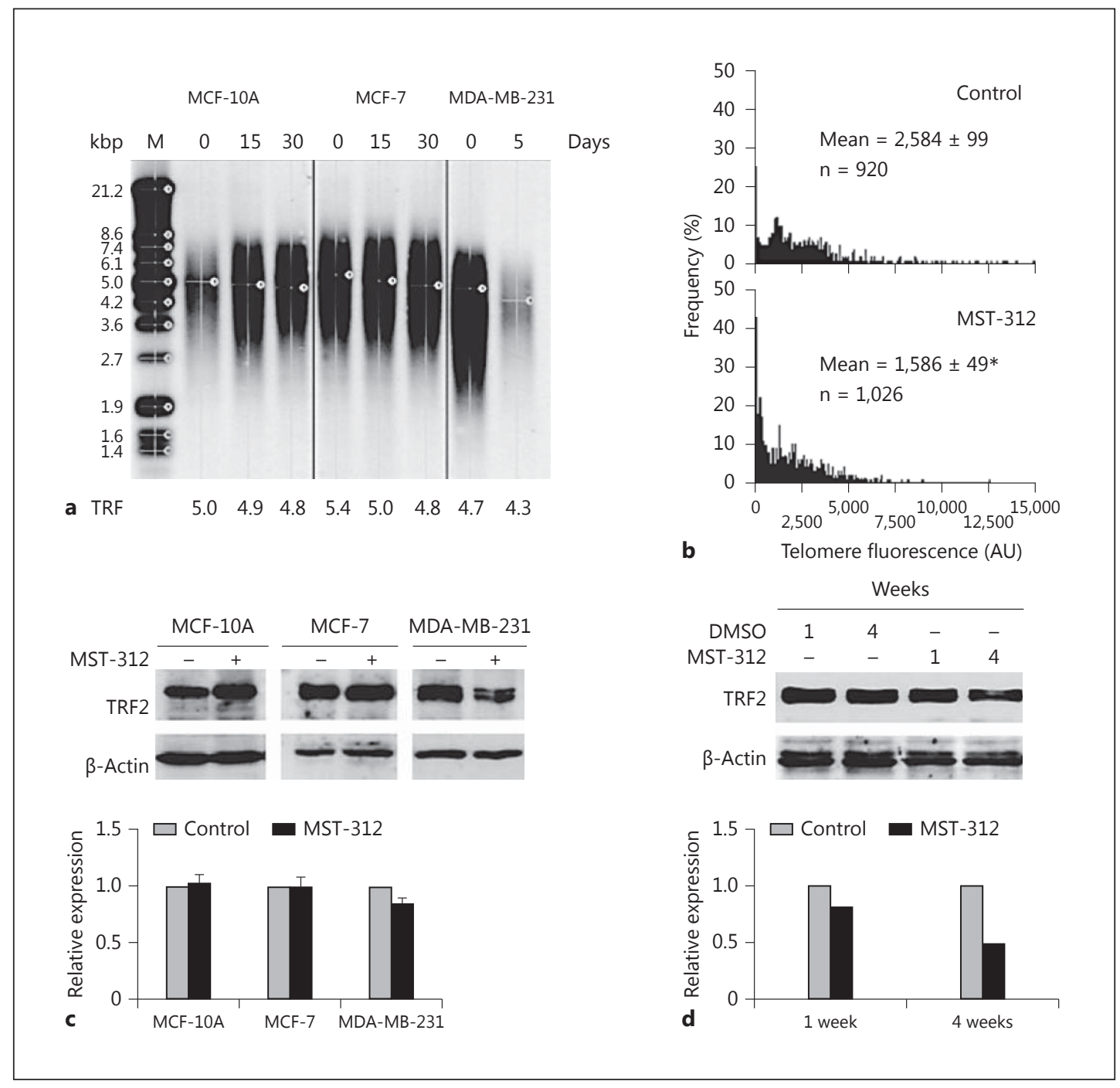

Fig. 2. MST-312 induces telomere shortening in breast cancer cells. a Genomic DNA was isolated from cells cultured in the absence or presence of MST-312 for the indicated number of days. Terminal restriction fragments were detected by Southern blotting using the TeloTAGGG telomere detection system. Representative images of three independent experiments are shown. b Telomere length analysis following treatment of MCF-7 cells with $1.0 \mu \mathrm{M}$ MST-312 for 30 days by Q-FISH showed a significant reduction in average telomere fluorescence intensity as compared to control cells. ${ }^{*} \mathrm{p}<0.05$ vs. respective controls. c Cell lysates were prepared from each cell line with or without MST-312 treatments $(1.0 \mu \mathrm{M}, 48 \mathrm{~h}) .30 \mu \mathrm{g}$ of protein was run on a $10 \%$ acrylamide SDS denaturing gel, and then transferred onto a Hybond P membrane. A primary anti-TRF2 antibody was used. $\beta$-Actin was used as an internal control. d TRF2 protein expression in MST-312-treated MCF-7 cells for the indicated number of weeks.

single-strand breaks. Breast cancer cells were treated with MST-312 (1.0 $\mu \mathrm{M})$ continuously for up to 7 days. As shown in figure 3b, a significant increase in DNA damage was detected in both cell types within $48 \mathrm{~h}$ of treatment. Interestingly, we observed that a similar level of increase in MST-312 DNA damage occurred at an earlier time point in MDA-MB-231 breast cancer cells compared to MCF-7 breast cancer cells. For instance, a 3-fold increase in MST312-induced DNA damage was observed in MCF-7 at 7 days posttreatment. In contrast, there was a 4-fold increase in DNA damage in MDA-MB-231 cells following 5 days of treatment with 


\section{Journal of \\ Nutrigenetics \\ Nutrigenomics}

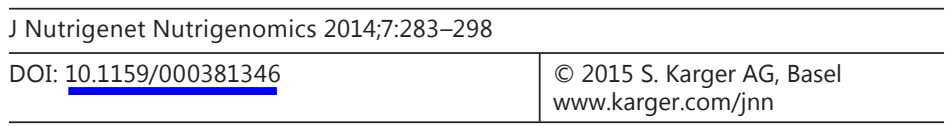

Gurung et al.: MST-312 Alters Telomere Dynamics, Gene Expression Profiles and Growth in Human Breast Cancer Cells

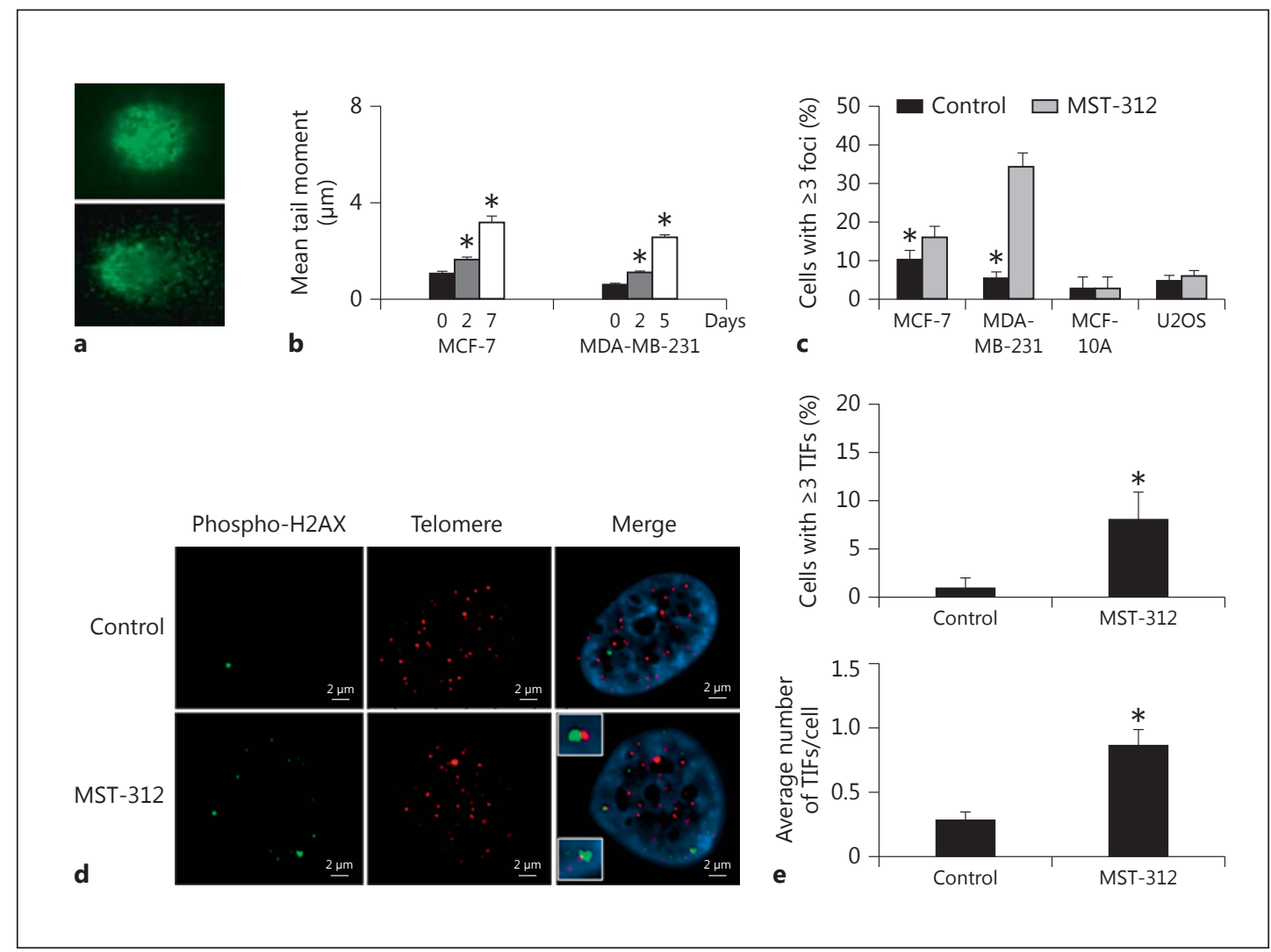

Fig. 3. MST-312 induces DNA damage and telomere dysfunction. a Representative images of normal (upper panel) and damaged (lower panel) nuclei following comet analysis from MDA-MB-231 cells treated with MST-312 for 5 days. $\mathbf{b}$ The extent of DNA damage was measured in terms of tail moment (fraction of DNA in the tail). MST-312 (1.0 $\mu \mathrm{M})$ treatment of MCF-7 (0, 2 and 7 days) and MDA-MB-231 (0, 2 and 5 days) induced significant DNA damage. c Percentage of $\gamma$-H2AX-positive cells following treatment with $1.0 \mu$ M MST-312 for $48 \mathrm{~h}$. A cell with three or more $\gamma$-H2AX was determined as positive for $\gamma$-H2AX. d, e Telomere dysfunctioninduced foci (TIFs) analysis following 48-hour treatment of MCF-7 cells with 1.0 $\mu \mathrm{M}$ MST-312. A significant increase in cells with TIFs was observed following MST-312 treatment. Data represent means \pm SE of three independent experiments. ${ }^{*} \mathrm{p}<0.05$ vs. respective controls. Images were captured using a Zeiss Axioplan Imaging fluorescent microscope with a $\times 63$ objective, and individual nuclei were processed using Adobe Photoshop CS5.1 (Adobe Systems Inc., USA) for better clarity and illustration.

MST-312 when compared to the respective control cells. Phosphorylation of H2AX $(\gamma-\mathrm{H} 2 \mathrm{AX})$ is generally accepted as a consistent and quantitative marker of DSBs, even under the conditions where only few DSBs are present [25, 26]. Following MST-312 treatment for $48 \mathrm{~h}$, there was a significant increase in the number of $\gamma$-H2AX-positive nuclei in MCF-7 and MDA-MB-231 cells. MDA-MB-231 cells exhibited a 30\% increase compared to a 6\% increase in MCF-7 cells (fig. 3c). For negative controls, DNA damage assay was done on telomerase-negative osteosarcoma cells, U2OS and noncancerous breast epithelial cells, MCF-10A. In these cells, we did not observe a significant increase in induced DSB following treatment with $1.0 \mu \mathrm{M}$ MST-312 for $48 \mathrm{~h}$, suggesting that MST-312-induced DNA damage is specific for telomerase-positive cancer cells. As TRF2 expression in MST-312-treated MCF-7 cells was unchanged following $48 \mathrm{~h}$ of treatment with MST-312, we evaluated telomere integrity in these cells using the TIF assay, and there was an increase in the percentage of TIF-positive MCF-7 cells following treatment with MST-312 for $48 \mathrm{~h}$ (fig. 3d, e). 
Gurung et al.: MST-312 Alters Telomere Dynamics, Gene Expression Profiles and Growth in Human Breast Cancer Cells

Reduced Cell Proliferation in Breast Cancer Cells following Treatment with MST-312

Initially, to determine the appropriate dose and time point for telomerase inhibition, a dose-response study was performed for 24-hour treatment of MCF-10A, MCF-7 and MDAMB-231 cells with MST-312 (fig. 4a). Breast cancer cells displayed a higher sensitivity to MST-312 compared to MCF-10A cells. MCF-7 and MDA-MB-231 cells were treated with MST-312 at various time points, and cell growth was determined with crystal violet dye and trypan blue exclusion assay. At $48 \mathrm{~h}$, treatment with MST-312 $(1.0 \mu \mathrm{M})$ led to a decrease in cell survival in both cell types tested, and further decline was observed in MCF-7 and MDA-MB-231 cells at the end of day 7 as compared to untreated cells and cells treated for $48 \mathrm{~h}$ (fig. 4b). There was a 15 and 18\% decrease in cell viability in MCF-7 cells and MDA-MB-231 cells, respectively, at the end of the 48-hour treatment. At the end of the 7-day treatment with MST-312 $(1.0 \mu \mathrm{M})$, MCF-7 cell survival further decreased to $70 \%$ relative to untreated controls (fig. 4a). On the other hand, the effect was more pronounced in MDA-MB-231 cells when treatment duration was increased. Following 7 days of treatment with MST-312 (1.0 $\mu \mathrm{M})$, only $17 \%$ of the cells survived (fig. 4b). A similar observation was made following trypan blue exclusion assay. The decrease in cell proliferation increased with the duration of MST-312 treatment, and a drastic reduction in cell proliferation in MDA-MB-231 cells was observed at the end of day 7 of drug treatment (fig. 4c). This differential response in cell growth between MCF-7 and MDA-MB-231 cell lines prompted us to analyze cell cycle progression after $48 \mathrm{~h}$ of treatment with MST-312.

Immediate growth inhibition in MCF-7 and MDA-MB-231 cells following MST-312 treatment was most probably due to the differential response in cell cycle progression. Following $48 \mathrm{~h}$ of MST-312 $(1.0 \mu \mathrm{M})$ treatment, a significant G2/M arrest was observed in MDA-MB-231 cells (fig. 4d). Expression of proteins involved in cell cycle regulation was studied in growth-arrested cells following MST-312 treatment (fig. 4e). Western blotting for cyclin B has demonstrated that MST-312 treatment reduces the expression of cyclin B as illustrated in figure 4e in MDA-MB-231 cells. In addition, we wanted to determine if growth arrest involved p21 protein expression, and we found that the expression of the p21 protein was significantly reduced in MST-312-treated MDA-MB-231 cells (fig. 4e). Although the p21 protein is essential in cell cycle arrest allowing repair of any DNA damage, lack of p21 has been shown to enhance apoptosis in cancer cells [27]. Cell cycle analysis performed on MST312-treated cells indicates that cells are arrested at different phases of the cell cycle, which is reminiscent of DNA damage induction.

\section{Downregulation of Genes Involved in HR Repair Pathway}

Microarray analysis was carried out in breast cancer cells and MCF-10A following exposure to $1.0 \mu \mathrm{M}$ MST-312 for $48 \mathrm{~h}$ to understand the impact of MST-312 in genes implicated in cell proliferation, cell cycle, apoptosis, telomere maintenance, DNA repair and recombination. We observed changes in the expression of genes involved in telomere maintenance, DNA repair, cell survival and apoptosis (fig. 5a), and validated these findings with RT-PCR (fig. 5b). A decrease in the expression of genes encoding proteins involved in prosurvival such as survivin, anaphase-promoting complex, M-phase phosphoprotein and cyclin B was observed in MST-312-treated cells. A decrease in the expression of the TIN2 gene, part of the shelterin complex essential in telomere maintenance via recruitment of telomerase to telomere [28], was also observed in breast cancer cells. Interestingly, there was an increase in the gene expression of TRF2 following MST-312 treatment in breast cancer cells.

As MST-312 induces DSBs in cancer cells, the most notable changes in genes coding for proteins involved in the HR DNA repair pathway were ATM, RAD50 and RAD51C (fig. 5a). ATM is a member of the phosphoinositol 3-kinase-related kinase family, and autophosphorylation at ser-1981 on ATM is required during ATM kinase activation initiated by DSBs in the genome [29]. RAD50 is a component of the MRE11/RAD50/NBN complex essential for 
Gurung et al.: MST-312 Alters Telomere Dynamics, Gene Expression Profiles and Growth in Human Breast Cancer Cells

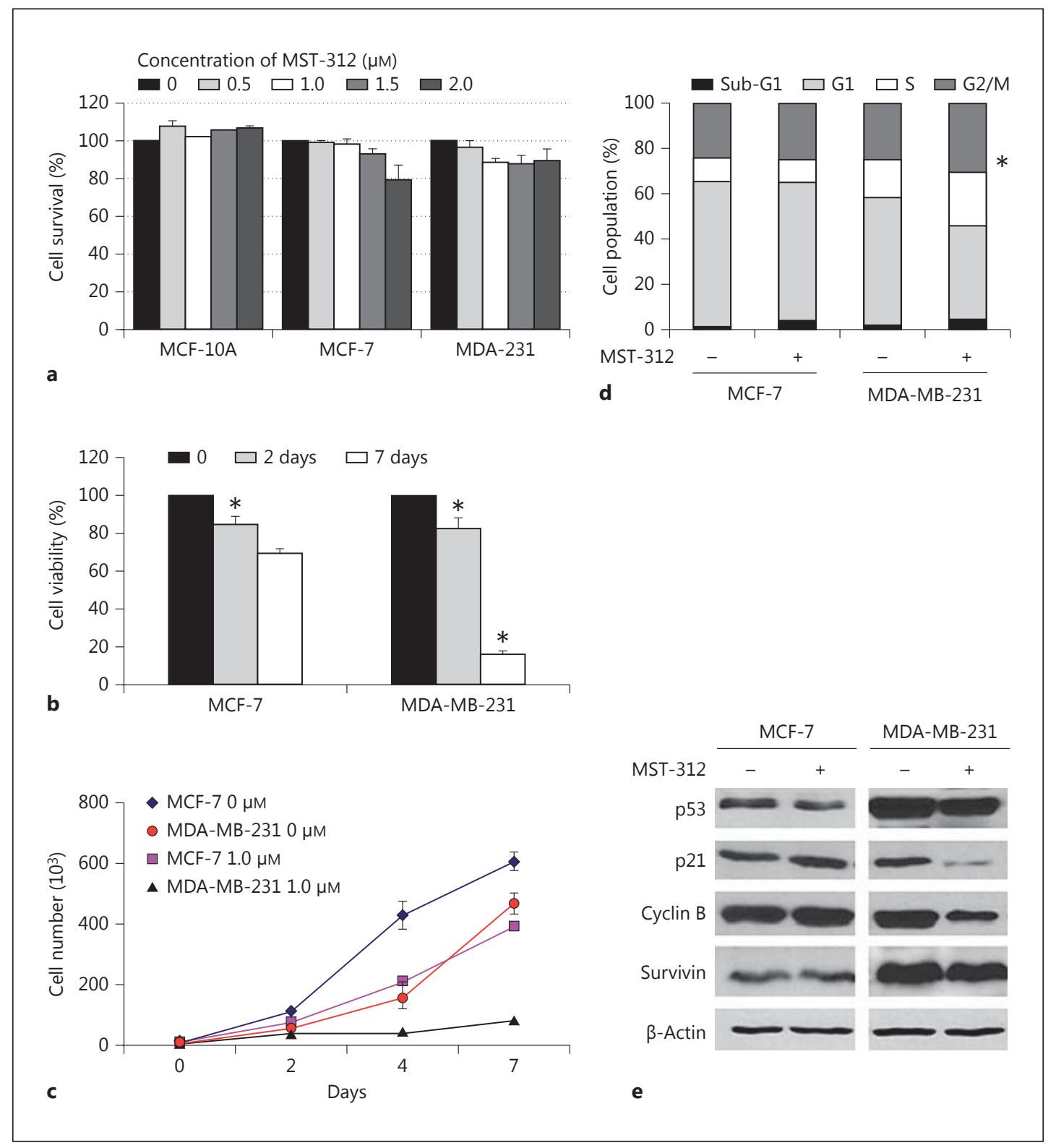

Fig. 4. Growth inhibition in breast cancer cell lines following MST-312 treatment. a Cell viability at $24 \mathrm{~h}$ following treatment with different concentrations of MST-312. b Crystal violet cell viability assay following treatment of MCF-7 and MDA-MB-231 cells with $1.0 \mu \mathrm{M}$ MST-312 for 0, 2 and 7 days. c Cell counting using trypan blue-exclusion assay was carried out following treatment with $1.0 \mu \mathrm{M}$ for the indicated number of days. d Cell cycle progression was analyzed after 48-hour treatment of MCF-7 and MDA-MB-231 cells with 1.0 $\mu \mathrm{M}$ MST-312. Growth arrest was attributed to a slight increase in sub-G1 (apoptotic) population and/ or G2/M phase arrest in MST-312-treated breast cancer cells. Asterisk indicates $\mathrm{p}<0.05$ as compared to the corresponding cell cycle stage in untreated controls. e Western blot analysis following 48-hour treatment with $1.0 \mu \mathrm{M}$ MST-312 was carried out in MCF-7 and MDA-MB-231 cells. Whole cells were lysed, and equal amounts of proteins were separated using 4-20\% SDS-PAGE, transferred to the PVDF membrane and immunoreacted with antibodies against p53, p21, survivin and cyclin B. $\beta$-Actin was used as the loading control. 
Gurung et al.: MST-312 Alters Telomere Dynamics, Gene Expression Profiles and Growth in Human Breast Cancer Cells

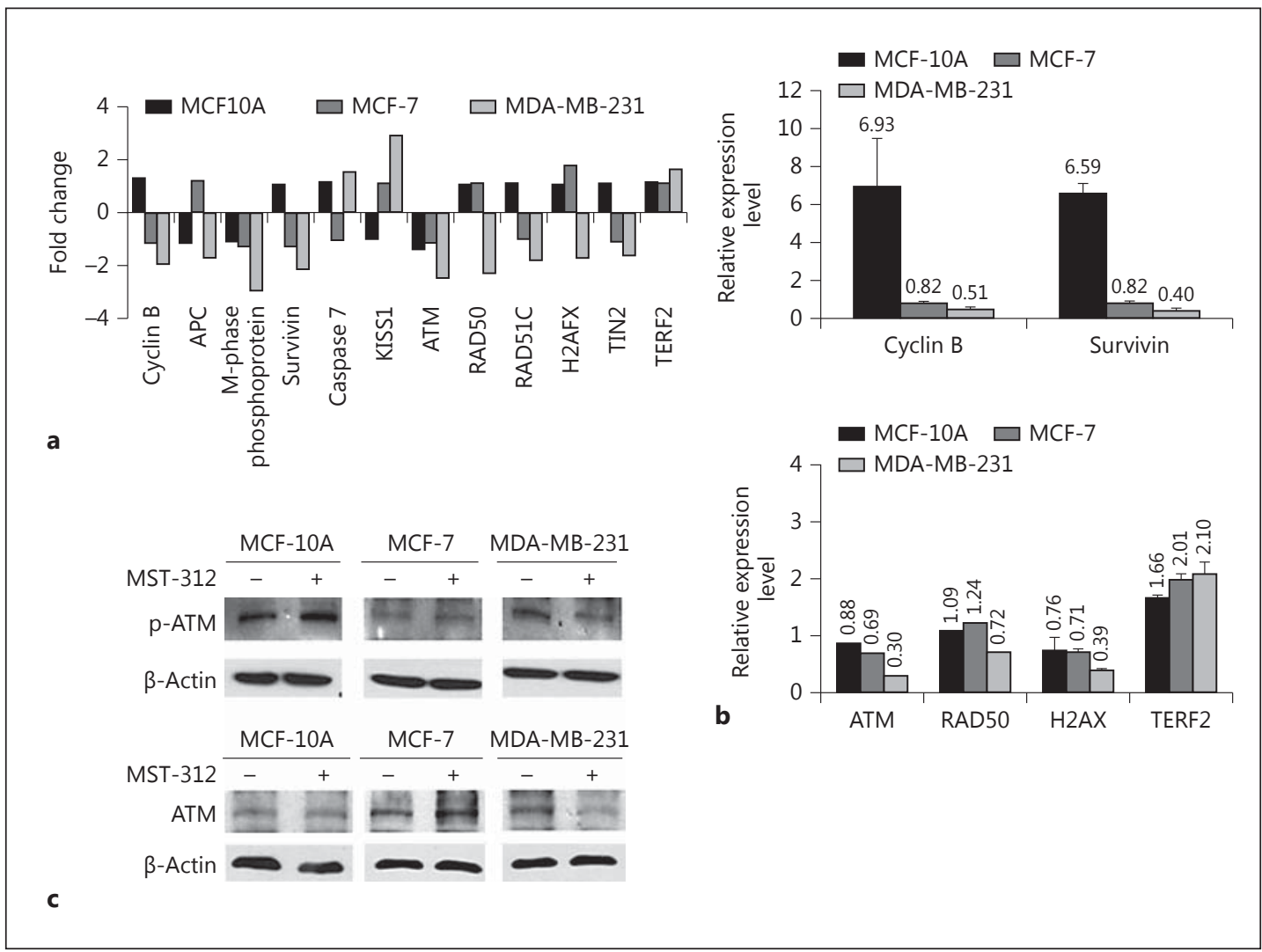

Fig. 5. Decrease in gene expression of the HR repair pathway proteins observed in breast cancer cells following MST-312 treatment. a Data for differentially expressed genes obtained following 48-hour treatment with $1.0 \mu \mathrm{M}$ MST-312 with fold change of $>2.0$ in at least one of the experimental conditions are represented. APC = Anaphase-promoting complex. $\mathbf{b}$ Relative expression of genes determined by RT-PCR in cells treated with $1.0 \mu \mathrm{M}$ MST-312. The level of expression was normalized against three housekeeping genes - actin, gapdh and hsp90. Most importantly, a decrease in the DNA repair gene ATM was observed in both breast cancer cells. Data represent means \pm SD of two independent experiments done in triplicate. c Protein expression of ATM and phospho-ATM following 48-hour treatment with $1.0 \mu \mathrm{M}$ MST-312. $\beta$-Actin was used as loading control. Representative images of three independent experiments are shown.

processing DNA DSBs as it facilitates ATM and ATR-dependent DNA damage signaling [30]. Following RT-PCR, there was a 32 and 71\% decrease in ATM gene expression in MCF-7 and MDA-MB-231 cells, respectively, as compared to their respective controls. More importantly, the gene expression levels of both ATM and RAD50 were significantly reduced in MDA-MB-231 cells (fig. 5a, b), which is consistent with our microarray results. Following protein expression analysis, we observed a reduced level of ATM expression in MDA-MB-231 cells. In addition, there was no activation of the ATM protein in these cells as demonstrated by Western blot analysis of p-ATM (ser-1981; fig. 5c).

\section{Inhibition of Telomerase along with PARP-1 Results in the Greatest Decrease in Cell \\ Survival in Breast Cancer Cells}

Recently, we have reported that telomerase inhibition along with PARP inhibition renders the cell sensitive to DNA-damaging agents [31]. Moreover, cells with telomere dysfunction are highly sensitive to genotoxic agents [32,33]. Studies have demonstrated that defects in the HR pathway increase the sensitivity to PARP-1 inhibition [34, 35]. Here, we show that MST-312 
Journal of
Nutrigenetics
Nutrigenomics

Fig. 6. Inhibition of PARP-1 and telomerase increases reduction in cell viability in breast cancer cells. Cell viability assay was determined using the CellTiter-Glo assay. Cells were treated with the PARP-1 inhibitor PJ-34 (10 $\mu \mathrm{M})$ and/or MST-312 (1.0 $\mu \mathrm{M})$ for $72 \mathrm{~h}$. The greatest reduction in cell viability was observed following combined inhibition of PARP-1 and telomerase. Data represent means \pm SE of three independent experiments which were done in triplicate. ${ }^{*} \mathrm{p}<0.05$ vs. respective controls.

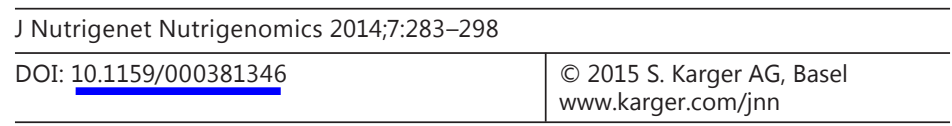

Gurung et al.: MST-312 Alters Telomere Dynamics, Gene Expression Profiles and Growth in Human Breast Cancer Cells

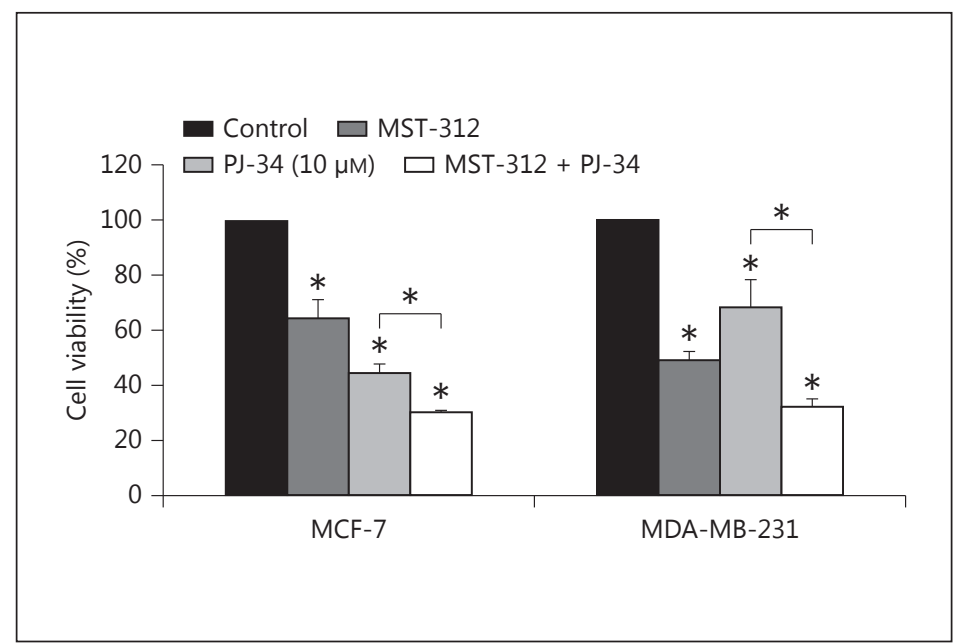

reduces ATM expression in breast cancer cells. Thus, we investigated whether telomeraseinhibited breast cancer cells were sensitive to PARP-1 inhibition. Breast cancer cells were treated with $10 \mu \mathrm{M}$ PJ-34, a potent PARP-1 inhibitor [21], along with MST-312 for $72 \mathrm{~h}$. PARP-1 inhibition alone reduced the viability of breast cancer cells as compared to their respective controls. There was a 56 and 32\% reduction in cell viability in MCF-7 and MDA-MB-231 cells, respectively, compared to untreated controls (fig. 6). Consistent with our findings of the greater sensitivity of MDA-MB-231, there was a 51\% reduction in cell viability in MDA-MB-231 cells compared to the $36 \%$ reduction in MCF-7 cells following MST-312 treatment for $72 \mathrm{~h}$. More importantly, the largest decrease in cell viability was achieved following dual inhibition of telomerase and PARP-1. There was a 70 and 68\% decrease in cell viability in MCF-7 and MDA-MB-231 cells, respectively, compared to untreated controls (fig. 6).

\section{Discussion}

Despite the continual progress in early detection of breast cancer, it is still the most common malignancy and a major contributor to cancer-related deaths in women [36]. In this study, we demonstrate that MST-312 inhibits telomerase activity, induces telomere dysfunction and reduces cell proliferation in breast cancer cells. The decrease in telomerase activity was not associated with changes in the gene or protein expression of the core components of telomerase such as TERT and TERC in breast cancer cells. However, we observed a reduction in the expression of TIN2, which is important in recruitment of telomerase to telomere in vivo [28]. Prolonged exposure to MST-312 resulted in telomere shortening and dysfunction, which is accompanied by reduced cell proliferation. This is in agreement with an earlier observation in another telomerase inhibitor, GRN163L [37, 38].

In most cancer cells, death following telomerase inhibition occurs after a lag period during which telomere length is reduced to below critical length. However, it has been shown that telomerase inhibition in cervical cancer cells induces apoptotic cell death within a few days, without a significant shortening of telomeres [39]. In contrast, telomerase inhibition in ovarian cancer cells led to immediate growth arrest without any apoptosis [40]. In our study, immediate reduction in cell growth due to cell cycle arrest (as demonstrated by a decrease in the Cyclin B gene and protein expression) was observed in MST-312-treated breast cancer cells MDA-MB-231 following $48 \mathrm{~h}$ of treatment. In our gene expression studies, we observed 
Gurung et al.: MST-312 Alters Telomere Dynamics, Gene Expression Profiles and Growth in Human Breast Cancer Cells

a decrease in the expression of the prosurvival gene survivin. However, at this time point $(48 \mathrm{~h})$ of posttreatment, the effect was only observed in mRNA expression level as protein expression analysis (fig. 4e) revealed minimal changes in the expression of the survivin protein. Collectively, these findings suggest that growth arrest rather than apoptotic cell death is the cause of reduction in cell proliferation. Moreover, there was a non-significant increase in the population of cells undergoing apoptosis based on our cell cycle analysis (fig. 4d). With the continual exposure to MST-312, there was a further reduction in breast cancer cell proliferative capacity associated with increased induction of DNA damage.

Telomeres function to protect DNA integrity, but unfortunately fragile sites and DNA damage can result at telomeric sites following disruption of telomere-telomerase homeostasis and the loss of telomere cap protection [41]. We observed an elevated level of DSBs as demonstrated by the presence of the $\gamma$-H2AX protein in breast cancer cells within 2 days after exposure to MST-312. Telomere dysfunction was further demonstrated by a slight but significant increase in TIF-positive cells in MCF-7. Gene expression data demonstrated a reduction in TIN2 expression in breast cancer cells compared to normal epithelial cells. TIN2 is part of the shelterin protein complex and is important in stabilizing the TRF2 complex [42]. Despite an increase in mRNA expression of the TRF2 gene in breast cancer cells following MST-312 treatment, there was no increase in TRF2 protein expression. Rather, we observed a decrease in TRF2 protein level with prolonged treatment of MST-312. Increased TRF2 mRNA expression could be a feedback response to telomere dysfunction as a recent study has shown that a higher level of TRF2 observed in advanced cancer cells with critically short telomeres may be important for the protective function of telomeres [43]. While a gradual telomere shortening was observed in MCF-7 cells following telomerase inhibition, a decrease in telomere length was observed 5 days after treatment with telomerase inhibitor in MDA-MB-231 cells. As TRF2 is essential for telomere protection, this rather early effect on telomere length could also be due to telomere deprotection due to a decrease in TRF2 expression in MDA-MB-231 cells. Studies performed in breast tissue arrays demonstrated a significant inverse relationship between a high expression of TRF2 protein and short telomeres within invasive breast carcinomas [43]. Since TRF2 inhibits telomerase and prevents activation of DNA damage response at the telomeres, the high level of TRF2 at short telomeres reflects the increased DNA repair capacity. A decrease in TRF2 protein expression could be due to a decrease in TIN2 mRNA expression as TIN2 stabilizes the TRF2 complex at telomeres [44].

Telomere-binding proteins such as TRF2 are critical for assuring that exposed telomeres do not trigger a DNA damage response [45]. In this regard, MST-312 induced acute DNA damage following telomerase inhibition in cancer cells inducing cell cycle arrest, especially in MDA-MB-231 cells. It has been shown that the knockdown of TRF2 triggers DNA damage responses via ATM activation [46]. ATM, a serine/threonine protein kinase, is essential for triggering the HR pathway in response to DNA lesions, and inhibition of ATM sensitizes breast cancer cells to radiation [47]. However, in our study, though the loss of the TRF2 protein was observed in MDA-MB-231cells, there was no activation of ATM protein kinase. These findings suggest that telomere dysfunction is essentially due to inhibition of telomerase activity. Unexpectedly though, we observed a reduced expression of ATM as well as RAD50 gene in MDA-MB-231 cells. A recent study has shown that reduced endogenous expression of telomerase in primary fibroblasts abrogates DNA damage repair by changing chromatin architecture and ATM activation [48]. It has also been reported that downregulation of ATM expression by microRNAs directly targeting the ATM-3'-UTR region also sensitizes cells to DNA damage [49]. Thus, it is possible that increased sensitivity of MDA-MB-231 to MST-312, increased DSBs and cell death could be associated with decreased expression of ATM.

Targeting DNA damage has been considered an attractive strategy to improve the effectiveness of genotoxic cancer therapy [50], and inhibition of PARP has been suggested as a thera- 
Gurung et al.: MST-312 Alters Telomere Dynamics, Gene Expression Profiles and Growth in Human Breast Cancer Cells

peutic strategy in the treatment of breast cancer cells [51]. Several studies have shown that inhibition of ATM via siRNA or pharmacological agents sensitizes cells to PARP-1 inhibitors [52-54]. Most importantly, recent reports have demonstrated that PARP-1 inhibition in BRCA1/2defective breast cancer cells showed synergistic lethality $[55,56]$. In line with these reports, we also observed a significant reduction in cell viability in breast cancer cells following PARP-1 inhibition. Based on our findings, we can suggest that MST-312-induced decrease in ATM expression might sensitize highly metastatic breast cancer cells (MDA-MB-231) to PARP-1 inhibition.

Cancer cells defective in any component of the HR pathway due to BRCA1/2 are more sensitive to PARP-1 inhibition [57]. We observed that the antiproliferative effects following telomerase inhibition with MST-312 were associated with decreased ATM levels, a DNA damage response protein important in the HR pathway. However, we did not observe a synergistic reduction in cell survival following dual inhibition of telomerase with MST-312 and PARP-1 with PJ-34. Nevertheless, the greatest reduction in cell viability was observed following dual inhibition compared to that after single inhibition. This rather small effect could be due to the short exposure time to dual inhibition, and prolonged treatment with both inhibitors could increase cell death in breast cancer cells.

It has been suggested that plant products provide additional benefits when treating cancer cells as they cause less toxicity in normal cells compared to chemical agents. In this study, we have shown that the EGCG-modified compound MST-312 targets telomerasepositive breast cancer cells by inhibiting telomerase activity and inducing DNA damage. Furthermore, we found that inhibition of PARP along with telomerase increases cell death in breast cancer cells. While PARP inhibition has been possible with the chemical inhibitor 3-AB, studies have shown that various plant products such flavonoids have potent PARP-1-inhibitory effects $[58,59]$. Compounds such as myricetin, quercetin and fisetin have been shown to have a competitive and noncompetitive action, while some, such as tricetin, are mostly competitive. Modulation of the NAD+ level also affects PARP activity. For example, niacin (vitamin $\mathrm{B}_{3}$ ) restriction depletes NAD+, a substrate for PARPs, thus preventing DNA damage repair and eventually causing apoptosis $[60,61]$.

Collectively, we have shown that MST-312 treatment in breast cancer cells leads to telomerase inhibition, telomere dysfunction and acute induction of DSBs resulting in growth arrest, which is more evident in the metastatic cell type MDA-MB-231. Nevertheless, this combined approach in targeting telomerase using MST-312 along with PARP-1 inhibition could be explored further and may provide an alternative strategy in breast cancer therapy.

\section{Acknowledgments}

This work was supported by grants from the Academic Research Fund (Tier 1, WBS R-185-000-217112), Ministry of Education, Singapore.

\section{Disclosure Statement}

The authors confirm that there are no conflicts of interest.

\section{References}

1 Hanahan D, Weinberg RA: The hallmarks of cancer. Cell 2000;100:57-70.

2 Kim NW, Piatyszek MA, Prowse KR, Harley CB, West MD, Ho PL, Coviello GM, Wright WE, Weinrich SL, Shay JW: Specific association of human telomerase activity with immortal cells and cancer. Science 1994;266: 2011-2015.

-3 Greider CW: Telomere length regulation. Annu Rev Biochem 1996;65:337-365. 
Gurung et al.: MST-312 Alters Telomere Dynamics, Gene Expression Profiles and Growth in Human Breast Cancer Cells

4 Wright WE, Piatyszek MA, Rainey WE, Byrd W, Shay JW: Telomerase activity in human germline and embryonic tissues and cells. Dev Genet 1996;18:173-179.

5 Nabetani A, Ishikawa F: Alternative lengthening of telomeres pathway: recombination-mediated telomere maintenance mechanism in human cells. J Biochem 2011;149:5-14.

6 Cong YS, Wright WE, Shay JW: Human telomerase and its regulation. Microbiol Mol Biol Rev 2002;66:407-425.

7 Harley CB: Telomere loss: mitotic clock or genetic time bomb? Mutat Res 1991;256:271-282.

-8 Blackburn EH: Switching and signaling at the telomere. Cell 2001;106:661-673.

9 de Lange T: Protection of mammalian telomeres. Oncogene 2002;21:532-540.

10 Smogorzewska A, van Steensel B, Bianchi A, Oelmann S, Schaefer MR, Schnapp G, de Lange T: Control of human telomere length by TRF1 and TRF2. Mol Cell Biol 2000;20:1659-1668.

11 de Lange T: Shelterin: the protein complex that shapes and safeguards human telomeres. Genes Dev 2005;19: 2100-2110.

12 Karlseder J, Broccoli D, Dai Y, Hardy S, de Lange T: p53- and ATM-dependent apoptosis induced by telomeres lacking TRF2. Science 1999;283:1321-1325.

13 Chen H, Li Y, Tollefsbol TO: Strategies targeting telomerase inhibition. Mol Biotechnol 2009;41:194-199.

14 Gurung RL, Lim HK, Venkatesan S, Lee PS, Hande MP: Targeting DNA-PKcs and telomerase in brain tumour cells. Mol Cancer 2014;13:232.

15 Seimiya H, Oh-hara T, Suzuki T, Naasani I, Shimazaki T, Tsuchiya K, Tsuruo T: Telomere shortening and growth inhibition of human cancer cells by novel synthetic telomerase inhibitors MST-312, MST-295, and MST-1991. Mol Cancer Ther 2002;1:657-665.

16 Serrano D, Bleau AM, Fernandez-Garcia I, Fernandez-Marcelo T, Iniesta P, Ortiz-de-Solorzano C, Calvo A: Inhibition of telomerase activity preferentially targets aldehyde dehydrogenase-positive cancer stem-like cells in lung cancer. Mol Cancer 2011;10:96.

17 Jeggo PA: DNA repair: PARP - another guardian angel? Curr Biol 1998;8:R49-R51.

18 d'Adda di Fagagna F, Hande MP, Tong WM, Lansdorp PM, Wang ZQ, Jackson SP: Functions of poly(ADP-ribose) polymerase in controlling telomere length and chromosomal stability. Nat Genet 1999;23:76-80.

19 Seimiya H: The telomeric PARP, tankyrases, as targets for cancer therapy. Br J Cancer 2006;94:341-345.

-20 Seimiya H, Muramatsu Y, Ohishi T, Tsuruo T: Tankyrase 1 as a target for telomere-directed molecular cancer therapeutics. Cancer Cell 2005; 7:25-37.

-21 Chevanne M, Zampieri M, Caldini R, Rizzo A, Ciccarone F, Catizone A, D’Angelo C, Guastafierro T, Biroccio A, Reale A, Zupi G, Caiafa P: Inhibition of PARP activity by PJ-34 leads to growth impairment and cell death associated with aberrant mitotic pattern and nucleolar actin accumulation in M14 melanoma cell line.J Cell Physiol 2010;222:401-410.

-22 Hande MP, Samper E, Lansdorp P, Blasco MA: Telomere length dynamics and chromosomal instability in cells derived from telomerase null mice. J Cell Biol 1999;144:589-601.

23 Yasaei H, Slijepcevic P: Defective Artemis causes mild telomere dysfunction. Genome Integr 2010;1:3.

-24 Takai H, Smogorzewska A, de Lange T: DNA damage foci at dysfunctional telomeres. Curr Biol 2003;13:15491556.

25 Banáth JP, Olive PL: Expression of phosphorylated histone H2AX as a surrogate of cell killing by drugs that create DNA double-strand breaks. Cancer Res 2003;63:4347-4350.

-26 Mah LJ, El-Osta A, Karagiannis TC: $\gamma$ H2AX: a sensitive molecular marker of DNA damage and repair. Leukemia 2010;24:679-686.

27 Hemmati PG, Normand G, Verdoodt B, von Haefen C, Hasenjager A, Guner D, Wendt J, Dorken B, Daniel PT: Loss of p21 disrupts p14ARF-induced G1 cell cycle arrest but augments p14ARF-induced apoptosis in human carcinoma cells. Oncogene 2005;24:4114-4128.

-28 Abreu E, Aritonovska E, Reichenbach P, Cristofari G, Culp B, Terns RM, Lingner J, Terns MP: TIN2-tethered TPP1 recruits human telomerase to telomeres in vivo. Mol Cell Biol 2010;30:2971-2982.

29 Morrison C, Sonoda E, Takao N, Shinohara A, Yamamoto K, Takeda S: The controlling role of ATM in homologous recombinational repair of DNA damage. EMBO J 2000;19:463-471.

-30 Stiff T, Reis C, Alderton GK, Woodbine L, O'Driscoll M, Jeggo PA: Nbs1 is required for ATR-dependent phosphorylation events. EMBO J 2005;24:199-208.

31 Gurung R, Balakrishnan L, Bhattacharjee R, Manikandan J, Swaminathan S, Hande MP: Inhibition of poly (ADPribose) polymerase-1 in telomerase deficient mouse embryonic fibroblasts increases arsenite-induced genome instability. Genome Integr 2010;1:5.

-32 Newman JPA, Banerjee B, Fang W, Poonepalli A, Balakrishnan L, Low GKM, Bhattacharjee RN, Akira S, Jayapal M, Melendez AJ, Baskar R, Lee H-W, Hande MP: Short dysfunctional telomeres impair the repair of arseniteinduced oxidative damage in mouse cells. J Cell Physiol 2008;214:796-809.

33 Poonepalli A, Balakrishnan L, Khaw AK, Low GK, Jayapal M, Bhattacharjee RN, Akira S, Balajee AS, Hande MP: Lack of poly(ADP-ribose) polymerase-1 gene product enhances cellular sensitivity to arsenite. Cancer Res 2005;65:10977-10983.

-34 Kyle S, Thomas HD, Mitchell J, Curtin NJ: Exploiting the Achilles heel of cancer: the therapeutic potential of poly(ADP-ribose) polymerase inhibitors in BRCA2-defective cancer. Br J Radiol 2008;81(special issue 1):S6-S11.

35 McCabe N, Turner NC, Lord CJ, Kluzek K, Białkowska A, Swift S, Giavara S, O’Connor MJ, Tutt AN, Zdzienicka MZ, Smith GCM, Ashworth A: Deficiency in the repair of DNA damage by homologous recombination and sensitivity to poly(ADP-ribose) polymerase inhibition. Cancer Res 2006;66:8109-8115. 


\section{Nutrigenetics Nutrigenomics}

\begin{tabular}{l|l}
\hline J Nutrigenet Nutrigenomics 2014;7:283-298 \\
\hline DOI: $10.1159 / 000381346$ & $\begin{array}{l}\text { @ 2015 S. Karger AG, Basel } \\
\text { www.karger.com/jnn }\end{array}$ \\
\hline
\end{tabular}

Gurung et al.: MST-312 Alters Telomere Dynamics, Gene Expression Profiles and Growth in Human Breast Cancer Cells
36

-37

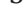

$-38$ breast cancer. Breast Cancer Res Treat 2006;96:73-81.

DeSantis C, Siegel R, Bandi P, Jemal A: Breast cancer statistics, 2011. CA Cancer J Clin 2011;61:408-418. Gellert G, Dikmen Z, Wright W, Gryaznov S, Shay J: Effects of a novel telomerase inhibitor, GRN163L, in human

Hochreiter AE, Xiao H, Goldblatt EM, Gryaznov SM, Miller KD, Badve S, Sledge GW, Herbert B-S: Telomerase template antagonist GRN163L disrupts telomere maintenance, tumor growth, and metastasis of breast cancer. Clin Cancer Res 2006;2006;12:3184-3192.

-39 Yatabe N, Kyo S, Kondo S, Kanaya T, Wang Z, Maida Y, Takakura M, Nakamura M, Tanaka M, Inoue M: 2-5A antisense therapy directed against human telomerase RNA inhibits telomerase activity and induces apoptosis without telomere impairment in cervical cancer cells. Cancer Gene Ther 2002;9:624-630.

40 Luo Y, Yi Y, Yao Z: Growth arrest in ovarian cancer cells by hTERT inhibition short-hairpin RNA targeting human telomerase reverse transcriptase induces immediate growth inhibition but not necessarily induces apoptosis in ovarian cancer cells. Cancer Invest 2009;27:960-970.

41 Tamakawa RA, Fleisig HB, Wong JMY: Telomerase inhibition potentiates the effects of genotoxic agents in breast and colorectal cancer cells in a cell cycle-specific manner. Cancer Res 2010;70:8684-8694.

-42 Ye JZ-S, Donigian JR, van Overbeek M, Loayza D, Luo Y, Krutchinsky AN, Chait BT, de Lange T: TIN2 Binds TRF1 and TRF2 simultaneously and stabilizes the TRF2 complex on telomeres. J Biol Chem 2004;279:47264-47271. Diehl M, Idowu M, Kimmelshue K, York T, Jackson-Cook C, Turner K, Holt S, Elmore L: Elevated TRF2 in advanced breast cancers with short telomeres. Breast Cancer Res Treat 2011;127:623-630.

-44 Ye JZ, Donigian JR, van Overbeek M, Loayza D, Luo Y, Krutchinsky AN, Chait BT, de Lange T: TIN2 binds TRF1 and TRF2 simultaneously and stabilizes the TRF2 complex on telomeres. J Biol Chem 2004;279:47264-47271.

45 Deng Y, Chang S: Role of telomeres and telomerase in genomic instability, senescence and cancer. Lab Invest 2007; 87:1071-1076.

46 Denchi EL, de Lange T: Protection of telomeres through independent control of ATM and ATR by TRF2 and POT1. Nature 2007;448:1068-1071.

47 Cowell IG, Durkacz BW, Tilby MJ: Sensitization of breast carcinoma cells to ionizing radiation by small molecule inhibitors of DNA-dependent protein kinase and ataxia telangiectasia mutated. Biochem Pharmacol 2005;71: $13-20$.

48 Masutomi K, Possemato R, Wong JMY, Currier JL, Tothova Z, Manola JB, Ganesan S, Lansdorp PM, Collins K, Hahn WC: The telomerase reverse transcriptase regulates chromatin state and DNA damage responses. Proc Natl Acad Sci USA 2005;102:8222-8227.

-49 Song L, Lin C, Wu Z, Gong H, Zeng Y, Wu J, Li M, Li J: miR-18a impairs DNA damage response through downregulation of ataxia telangiectasia mutated (ATM) kinase. PLoS One 2011;6:e25454.

50 Ljungman M: Targeting the DNA damage response in cancer. Chem Rev 2009;109:2929-2950.

51 Orlando L, Schiavone P, Fedele P, Calvani N, Nacci A, Cinefra M, D’Amico M, Mazzoni E, Marino A, Sponziello F, Morelli F, Lombardi L, Silvestris N, Cinieri S: Poly (ADP-ribose) polymerase (PARP): rationale, preclinical and clinical evidences of its inhibition as breast cancer treatment. Expert Opin Ther Targets 2012;16(suppl 2):S83-S89.

52 Aguilar-Quesada R, Munoz-Gamez J, Martin-Oliva D, Peralta A, Valenzuela MT, Matinez-Romero R, QuilesPerez R, Murcia J, de Murcia G, de Almodovar M, Oliver FJ: Interaction between ATM and PARP-1 in response to DNA damage and sensitization of ATM deficient cells through PARP inhibition. BMC Mol Biol 2007;8:29.

53 Efimova EV, Mauceri HJ, Golden DW, Labay E, Bindokas VP, Darga TE, Chakraborty C, Barreto-Andrade JC, Crawley C, Sutton HG, Kron SJ, Weichselbaum RR: Poly(ADP-ribose) polymerase inhibitor induces accelerated senescence in irradiated breast cancer cells and tumors. Cancer Res 2010;70:6277-6282.

54 Shiloh Y: The ATM-mediated DNA-damage response: taking shape. Trends Biochem Sci 2006;31:402-410.

55 Bryant HE, Schultz N, Thomas HD, Parker KM, Flower D, Lopez E, Kyle S, Meuth M, Curtin NJ, Helleday T: Specific killing of BRCA2-deficient tumours with inhibitors of poly(ADP-ribose) polymerase. Nature 2005; 434:913-917.

56 Tutt A, Robson M, Garber JE, Domchek SM, Audeh MW, Weitzel JN, Friedlander M, Arun B, Loman N, Schmutzler RK, Wardley A, Mitchell G, Earl H, Wickens M, Carmichael J: Oral poly(ADP-ribose) polymerase inhibitor olaparib in patients with BRCA1 or BRCA2 mutations and advanced breast cancer: a proof-of-concept trial. Lancet 2010;376:235-244.

57 Helleday T, Bryant HE, Schultz N: Poly(ADP-ribose) polymerase (PARP-1) in homologous recombination and as a target for cancer therapy. Cell Cycle 2005;4:1176-1178.

58 Geraets L, Moonen HJ, Brauers K, Wouters EF, Bast A, Hageman GJ: Dietary flavones and flavonoles are inhibitors of poly(ADP-ribose)polymerase-1 in pulmonary epithelial cells. J Nutr 2007;137:2190-2195.

59 Weseler AR, Geraets L, Moonen HJ, Manders RJ, van Loon LJ, Pennings HJ, Wouters EF, Bast A, Hageman GJ: Poly (ADP-ribose) polymerase-1-inhibiting flavonoids attenuate cytokine release in blood from male patients with chronic obstructive pulmonary disease or type 2 diabetes. J Nutr 2009;139:952-957.

60 Benavente CA, Jacobson EL: Niacin restriction upregulates NADPH oxidase and reactive oxygen species (ROS) in human keratinocytes. Free Radic Biol Med 2008;44:527-537.

61 Benavente CA, Schnell SA, Jacobson EL: Effects of niacin restriction on sirtuin and PARP responses to photodamage in human skin. PLoS One 2012;7:e42276. 